\title{
Sözsüz Yakınlık ölçeğinin Türkçe Versiyonu İçin Geçerlik ve Güvenirlik Çalıșması
}

\author{
Mestan Küçük ${ }^{1}$ \\ Nevzat Bilge İspir ${ }^{2}$
}

Öz

Bu araştırmanın amacı Richmond, McCroskey ve Johnson (2003) tarafından geliştirilen Sözsüz Yakınlık Ölçeğini (SYÖ) Türkçeye uyarlamak ve ölçeğin geçerlik ve güvenirlik analizlerini gerçekleştirmektir. Araştırmaya Anadolu Üniversitesi, İletişim Bilimleri Fakültesi'nde öğrenim gören 196 üniversite öğrencisi katılmıştır. SYÖ’nün Türkçeye uyumlaştırılması geri çeviri tekniğiyle yapılmıştır. Dilsel uyumlaştırılma yapıldıktan sonra geçerlik ve güvenirlik analizleri yapılmıştır. Yapılan açımlayıcı faktör analizi ve doğrulayıcı faktör analizleri sonuçları sormacanın orijinal formla tutarlı olduğunu göstermiştir. Doğrulayıcı faktör analizi sonuçları yapı geçerliğinin sağlandığını, Kompozit Güvenirlik $(0,94)$ ve Ayıklanmış Ortalama Varyans $(0,34)$ değerleri ise uyum geçerliliğinin olduğunu göstermektedir. Güvenilirlik katsayısı 0,94 bulunmuştur.

Anahtar Sözcükler: Yakınlık, Sözsüz Yakınlık, Geçerlik, Güvenirlik

\section{Validity And Reliability Study For Turkish Version of Nonverbal Immediacy Scale}

\begin{abstract}
The purpose of this study is to adopt the Nonverbal Immediacy Scale (NIS) develop by Richmond, McCroskey and Johnson (2003) into Turkish and to perform validity and reliability analyses of the scale. The NIS was applied to 196 students from the Communication Faculty of Anadolu University. Back translation technique was used to adapt the NIS into Turkish. After finalizing the language (translation) adaptation process, validity and reliability analyses were conducted.

Results from exploratory and confirmatory factor analyses demonstrated that the original form of NIS and its Turkish version were consistent in terms of hypothesized structure. Confirmatory factor analysis result shows that construct validity was confirmed, and Composite Reliability (0.94) and Average Variance Extracted (0.34) confirm concurrent validity. Reliability coefficient were found to be 0.94 .
\end{abstract}

Keywords: Immediacy, Nonverbal Immediacy, Validity, Reliability

1 Yrd. Doç. Dr. Anadolu Üniversitesi, İletişim Bilimleri Fakültesi

2 Doç. Dr. Anadolu Üniversitesi, İletişim Bilimleri Fakültesi 


\section{Giriș}

B ireylerarası iletişim, iletişim bilimleri disiplininde önemli bir yer teşkil eden çaIışma alanlarından bir tanesidir. Ülkemizde bireylerarası iletişime ilişkin çeşitli yayınlara rastlanmaktadır ancak eğitim ve öğretimde, öğretici ile öğrenenin kurduğu iletişim konusunda çok yaygın çalışmalara rastlanılmamaktadır (Genç-Kumtepe ve Küçük, 2015).

Yurt dışındaki araştırmacılar öğretici-öğrenci ilişkilerinin doğası gereği bireylerarası olduğu ve diğer bireylerarası ilişkilerle benzerlikleri bulunduğu varsayımından yola çıkarak öğretici davranışlarını yoğun bir şekilde inceleme konusu yapmışlardır. Bunun temelinde de öğretici ve öğrenen arasında bireylerarası iletişim aracılığıyla gelişen ilişkinin öğrenmeyi doğrudan ve dolaylı olarak etkilemesi yatmaktadır. Yurt dışındaki çalışmalarda, öğreticilerin iletişim davranışları konusunda en yoğun olarak incelenen değişkenlerden bir tanesi yakınlık (immediacy) davranışlarıdır.

\section{Yakınlık Kavramı}

İlk olarak Mehrabian (1969) tarafından ortaya atılan bir kavramdır. Mehrabian'ın sözelve sözsüz yakınlık davranışlarına ilişkin çalışmaları hoşlanmanın yakınlık davranışlarına neden olduğunu destekler niteliktedir. Bu sonuç, yakınlık davranışlarının niçin ortaya çıktığını psikoloji temelinde açıklamaktadır. İçten gelen etkiler yakınlık davranışlarının oluşmasına neden olmaktadır. Bununla birlikte bu iç etkiler olmasa da (hoşlanma ya da beğenme gibi) bireyler bu davranışları sergileyebilir (Richmond, McCroskey ve Johnson, 2003).

Bu konuda çalışma yapan iletişim araştırmacılarının çoğu Mehrabian'ın bu konuda yaptığı temel çalışmayı kabul etseler de onun psikolojik yaklaşımını takip etmemişlerdir. Bunun yerine kurulan yakınlık davranışları odaklı iletişimin diğerleri üzerine etkilerini inceleyen araştırmalar yapmışlardır. Hoşlanma ya da beğenme yakınlık davranışlarına neden olur demek yerine, yakınlık davranışları hoşlanmaya ve beğenmeye neden olur demişlerdir. Yani insanların psikolojisinin nedeni olarak iletişim davranışları ortaya çıkar konusuna odaklanmak yerine insanların iletişim davranışlarının sonuçlarına odaklanmışlardır.

Araştırma konusuna yaklaşımdaki bu farklılıklar Mehrabian'ın ileri sürdüğü ilkeler yerine Richmond ve McCroskey (2000)'nin şu ilkeleri belirtmelerine neden olmuştur. "Yakınlık davranışlarını daha çok işe koşan iletişimciler diğerleri tarafından daha çok sevilir, daha iyi değerlendirilir ve daha çok tercih edilirler. Bu davranışları daha az işe koşan iletişimciler ise diğerleri tarafından pek sevilmez, olumsuz bir şekilde değerlendirilir ve iletişim kurma konusunda çok tercih edilmezler" (s.212). Bu iletişim bakış açısı, yakınlık davranışlarını, iletişimçinin kontrolü altında diğerlerinin tepkilerini etkileyen bir araç olarak göstermektedir.

Bu kavrama ve ölçülmesine yönelik iletişim araştırmaları, Andersen (1979)'in eğitim iletişimi ile ilgili çalışmalarıyla başlamıştır. Andersen, yükseköğretimde öğreticilerin yakınlık davranışlarının rolüne ilişkin çalışmalar yapmış ve bu kavrama ilişkin şu tanımı 
önermiştir: Yakınlık davranışları, öğretmenler ve öğrenciler arasındaki fiziksel ve / veya psikolojik mesafeyi azaltan sözsüz davranışlar olarak kavramsallaştırılabilir" (1979: 544). Bu tanım daha sonra Gorham (1988) tarafından, öğretmenler ve öğrenciler arasındaki psikolojik yakınlığı artıran sözlü etkileşimin dahil edilmesiyle genişletilmiştir. Richmond (2002: 65) yakınlık kavramını, "fiziksel ya da psikolojik yakınlık algısı olarak tanımlamıştır". Bu tanımlara göre yakınlık algısının çeşitli sözlü ve sözsüz iletişim davranışları aracılığıyla ortaya çıktığı belirtilebilir. Sözlü yakınlık, mizah kullanımı, öğrenci adının sık sık kullanııması, tartışmanın teşvik edilmesi, tartışmalardaki öğrenci yorumlarının dikkate alınması, öğrencilerle gelecekteki irtibatın teşvik edilmesi ve kişisel örneklerin paylaşımı içerir; Sözsüz yakınlık gülümseme, göz teması, sesli ifade gücü, açık ve olumlu jestler, rahat beden duruşu ve öğretici tarafından yapılan beden hareket davranışlarını içerir. Bu iletişim davranışları ve benzerleri iletişimde açıklığı, cana yakınlığı belirtir, bireylerarası iletişimde samimiyeti ve sıcaklığı arttırır.

Bu çalışmada araştırmacılar, iletişim davranışları içerisinde önemli bir yer teşkil eden ve iletişim çalışmalarında yoğun bir şekilde araştırmalara konu olan sözsüz yakınlık davranışlarının ölçülmesi amacıyla Richmond, McCroskey ve Johnson (2003) tarafından geliştirilen ölçeğin Türkçeye uyarlamasını gerçekleştirmişlerdir.

\section{Yöntem}

Çalışmaya, Anadolu Üniversitesi, İletişim Bilimleri Fakültesi öğrencileri katılımışır. Hazırlanan soru formu bir hafta boyunca, farklı günlerde, öğrenci kantininde öğrencilere dağıtılmış ve en son dersinden çıktıkları öğretim üyesini düşünerek ifadelere cevap vermeleri istenmiştir. Böylece, mümkün olduğunca farklı öğretim üyelerinin değerlendirilmesi sağlanmaya çalışılmıştır. 217 öğrenciden veri toplanmış, kullanılabilir form sayısı 196 olmuştur. Çalışmaya katılanların \%57,1'i erkek, \%41,8'i kadındır.

Çalışmada kullanılan Sözsüz Yakınlık Ölçeği, (Nonverbal Immediacy Scale) Richmond, McCroskey ve Johnson'un (2003) çalışmasından Türkçeye uyarlanmıştır. Ölçek, öncelikle üniversitede İngilizce dil eğitimi veren bir öğretim üyesince Türkçeye çevrilmiş, daha sonra Türkçe ifadeler İngilizceye yeniden çevrilmiş ve aralarındaki tutarsızlıklar incelenmiştir. Çeviri üzerinde uzlaşı sağlandıktan sonra ifadeler üzerinde hem anlam ve hem de cümle yapısı açısından düzeltmeler yapılmıştır.

Hazırlanan formun öncelikle 20 öğrenci üzerinde ön denemesi yapılmıştır. Bu ön denemeden hemen sonra öğrencilerin sorular hakkındaki görüşleri alınmıştır. Net olarak anlayamadıkları, onlara çok açık gelmeyen sorular belirlenmiş ve bu ifadeler üzerinde tartışılarak, ifadelerin anlamlarını bozmadan gerekli düzeltmeler yapılmıştır. Örneğin: "Insanlarla konuşurken ona dokunulduğunda, kendisine dokunan kişilerden uzaklaşır" ifadesi, "İnsanlarla konuşurken kendisine dokunulduğunda, dokunanlardan uzaklaşır" şeklinde değiştirilmiştir.

5’li Likert ölçüm düzeyinde yapılandırılan ölçekte 26 ifade yer almaktadır. Çeviri ve uyarlama çalışmasından sonra ölçeğin son hali aşağıdaki şekilde olmuştur. 
Tablo 1. Sözsüz Yakınlık Ölçeği

Aşağıdaki ifadeler, kişilerin sizinle konuşurken sergiledikleri bazı iletişim davranışlarını tanımlamaktadır.

Bu ifadeleri en son dersinden çıktığınız öğretim elemanının davranışlarını göz önünde bulundurarak doldurunuz.

Her bir ifadenin yanındaki boşluğa aşağıdaki ölçeğe göre uygun olan rakamı yazınız.

$1=$ Asla $2=$ Nadiren $3=$ Zaman zaman $4=$ Sıklıkla $5=$ Her zaman

İnsanlarla konuşurken...

1. ___... el ve kol hareketlerini kullanır.

2 . __... onların omzuna ya da koluna dokunur.

3. ___... tekdüze ya da cansız bir ses tonu kullanır.*

4. ___... onlara öylesine bakar ya da gözlerini kaçırır.*

5. ___... kendisine dokunulduğunda, dokunanlardan uzaklaşır *

6 . __... rahat bir vücut duruşuna sahiptir.

7. __.... kaşlarını çatar. *

8. ___... konuşurken göz temasından kaçınır. *

9 . __.... gergin bir vücut duruşuna sahiptir. *

10. ___... konuştuklarına yakın bir yerde durur ya da oturur.

11. __... konuşma sırasındaki ses tonu tekdüze ya da cansızdır. *

12. ___... çeşitli ses tonlamaları kullanır.

13 . __... beden dilini kullanır.

14. ___... çok hareketli ve canlıdır.

15. ___... yavan bir yüz ifadesine sahiptir. *

16. ... onlara doğru yaklaşır.

17.

18. .. doğrudan onlara bakar.

19. ... birçok farklı ses tonlamaları kullanır.

20. ... el kol hareketleri yapmaktan kaçınır.*

21. ___... insanlara doğru eğilir.

22. ___... göz temasını sürdürür.

23. ... onlara yakın oturmamaya ya da yakın durmamaya çalışır.*

24. .. karşısındakinden uzak durur. *

25. onlara gülümser.

26. onlara dokunmaktan kaçınır.*

\section{*Ters kodlanan ifadeler}

Verileri analizi sürecinde yapı geçerliği için açımlayıcı faktör analizi ve Doğrulayıcı faktör analizi uygulanmıştır. İlk olarak verilerin faktör analizine uygunluğu test edilmiştir. Bu amaçla, Kaiser-Meyer-Olkin (KMO) olarak adlandırılan örneklem uygunluk ölçüsü ve 
Bartlett'in Spherecity testi olarak adı verilen Bartlett küresellik testi gerçekleştirilmiştir. Güvenirliğini değerlendirmek için Cronbach alfa iç tutarlık katsayısı hesaplanmıştır. Toplanan veride kayıp veri bulunmamaktadır.

\section{Bulgular}

Bu başlık altında araştırmada gerçekleştirilen geçerlik ve güvenirlik analizlerine yer verilmiştir.

\subsection{Geçerlik Analizi}

Geçerlik analizi için öncelikle açımlayıcı faktör analizi uygulanmıştır. Öncelikle verini faktör analizine uygunluğu, Kaiser-Meyer-Olkin (KMO) olarak adlandırılan örneklem uygunluk ölçüsü ve Bartlett'in Spherecity testi olarak adı verilen Bartlett küresellik testi gerçekleştirilmiştir. Verilerin faktör analizine uygunluğu için KMO değerinin 0,60'den büyük olması ve Bartlett küresellik testinin ise istatistiksel olarak anlamlı bulunması $(p<0,05)$ gerekmektedir (Tabachnick ve Fidell, 2007, s.614). Bu çalışmada, KMO değeri 0,91 ve Barlett küresellik testi ise anlamlı bulunmuştur ( $X 2=3187,71$; $s d=325$; $\mathrm{p}<0,001)$.

Faktör analizinde oblique (Promax) rotasyon tekniği kullanılmıştır. Orijinal ölçek tek boyutlu bir ölçek olduğundan rotasyon uygulanmamış faktör yükleri boyutluluğu test etmek için kullanılmıştır. Tek boyutlu ölçeklerde, faktör analizi sonucunda ilk faktörde ortaya çıkan rotasyon edilmemiş faktör yüklerinin 0,40'ın üzerinde olması gerekmektedir (Hatcher, 1994). 26 ifade için elde edilen faktör yükleri Tablo 2'de görülmektedir.

Tablo 2. Rotasyon Edilmemiş illk Faktör Yükleri

\begin{tabular}{|c|c|c|c|}
\hline Ifadeler & Faktör Yükü & Ifadeler & Faktör yükü \\
\hline ifade 1 & 0,50 & ifade 14 & 0,82 \\
\hline ifade 2 & 0,45 & ifade 15 & 0,76 \\
\hline ifade 3 & 0,75 & ifade 16 & 0,63 \\
\hline ifade 4 & 0,67 & ifade 17 & 0,61 \\
\hline ifade 5 & 0,25 & ifade 18 & 0,60 \\
\hline ifade 6 & 0,70 & ifade 19 & 0,77 \\
\hline ifade 7 & 0,50 & ifade 20 & 0,51 \\
\hline ifade 8 & 0,64 & ifade 21 & 0,53 \\
\hline ifade 9 & 0,69 & ifade 22 & 0,71 \\
\hline ifade 10 & 0,50 & ifade 23 & 0,68 \\
\hline ifade 11 & 0,80 & ifade 24 & 0,67 \\
\hline ifade 12 & 0,76 & ifade 25 & 0,74 \\
\hline ifade 13 & 0,72 & ifade 26 & 0,52 \\
\hline
\end{tabular}


Faktör yükleri incelendiğinde, 5 . ifade hariç tüm faktör yüklerinin 0,40 'ın üzerinde olduğu görülmektedir. 5. ifade üzerinde düşünüldüğünde dokunma eylemi ile gerçekleşen şahıslardan uzaklaşma üzerine bir gönderme yaptığı görülmektedir. Buradaki uzaklaşma durumu yanıtlayıcılar tarafından sohbeti kesip gitme gibi algılanmış olabilir. Elde edilen faktör yükünün oldukça düşük olmasına rağmen ifadenin ölçekte kalmasına karar verilmiştir. Ancak sonraki çalışmalarda bu sorun göz önünde bulundurulmalıdır.

Sözsüz Yakınlık Ölçeği'nin Türkçe formundan elde edilen sonuçlar ikinci aşamada birinci düzey doğrulayıcı faktör analizine tabi tutulmuştur. Ölçüm modelinin uyum iyiliğinin belirlenmesinde ki-kare serbestlik derecesi oranı yanında çoklu uyum indekslerinden Uyum İyiliği İndeksi (Goodness of Fit Index- GFI), Normlaştırılmış Uyum İndeksi (Normed Fit Index- NFI), Karşılaştırmalı Uyum İndeksi (Comparative Fit Index- CFI), Standartlaştırılmış Ortalama Hataların Karekökü (Standardized Root Mean Square Residuel, SRMR) ve Yaklaşık Hataların Ortalama Karekökü (Root Mean Square Error of Approximation, RMSEA) uyum indeksleri kullanılmıştır. Uyum iyiliklerini değerlendirilmesinde GFI, NFI, CFI için 0,90'ın üzerinde olması, SRMR 0,08 'in ve RMSEA 0,10'un altında olması kıstasları kullanılmıştır (Hooper, Coughlan, ve Mullen 2008).

Tablo 3. Birinci Düzey DFA Sonucu ve Ölçüm Modelin Uyum İndeksleri ( $n=196)$

\begin{tabular}{llcl}
\hline Madde & $\mathrm{l}(\mathrm{sh})$ & $\mathrm{R}^{2}$ \\
\hline 1 & $0,50(0,07)$ & 0,25 \\
2 & $0,44(0,06)$ & 0,20 \\
3 & $0,76(0,08)$ & 0,58 \\
4 & $0,63(0,06)$ & 0,40 \\
5 & $0,21(0,07)$ & 0,04 \\
6 & $0,74(0,06)$ & 0,47 \\
7 & $0,45(0,07)$ & 0,20 \\
8 & $0,60(0,06)$ & 0,37 \\
9 & $0,65(0,07)$ & 0,42 \\
10 & $0,42(0,08)$ & 0,17 \\
11 & $0,82(0,08)$ & 0,68 \\
12 & $0,78(0,07)$ & 0,61 \\
13 & $0,71(0,06)$ & 0,50 \\
14 & $0,83(0,08)$ & 0,69 \\
15 & $0,75(0,08)$ & 0,56 \\
16 & $0,58(0,07)$ & 0,33 \\
17 & $0,56(0,07)$ & 0,31 \\
18 & $0,56(0,09)$ & 0,31 \\
19 & $0,79(0,07)$ & 0,63
\end{tabular}




\begin{tabular}{llll} 
& 20 & $0,52(0,06)$ & 0,27 \\
& 21 & $0,49(0,07)$ & 0,24 \\
& 22 & $0,66(0,07)$ & 0,44 \\
& 23 & $0,62(0,08)$ & 0,39 \\
& 24 & $0,59(0,08)$ & 0,34 \\
& 25 & $0,70(0,07)$ & 0,49 \\
& 26 & $0,48(0,09)$ & 0,23 \\
\hline Sd & & & \\
$\square^{2}$ & & & \\
प2/sd & & & \\
SRMR & & $1499,02(p<0.001)$ & \\
RMSEA & 4,9 & & \\
GFI & 0,08 & \\
NFI & 0,14 & & \\
CFI & 0,63 & & \\
IFI & 0,89 & \\
CR & 0,91 & & \\
AVE & 0,91 & & \\
\hline
\end{tabular}

Ayrıca uyum geçerliği testi için Kompozit Güvenirlik (composite reliability, CR) ve Ayıklanmış Ortalama Varyans (Average Variance Extracted, AVE) hesaplanmıştır. 


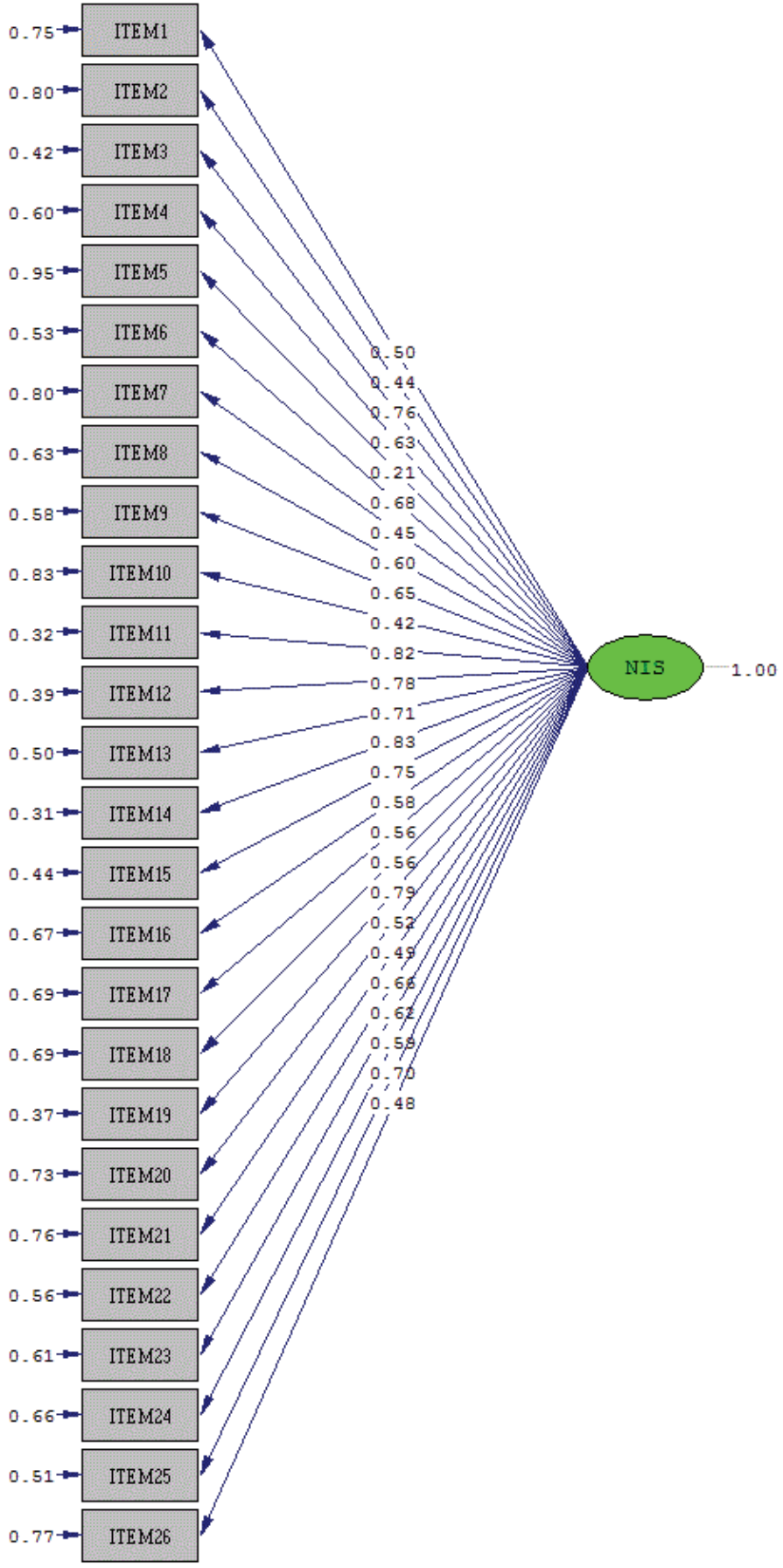

Şekil 1. Ölçüm Modelinin Birinci Düzey DFA Path Diyagramı 
Fornell ve Larcker (1981) iyi bir uyum geçerliği için CR (composite reliability) 0,8'in üzerinde olmasını AVE değerinin 0,5'in üzerinde olmasını önermektedir. DFA sonuçları Tablo 3'de görülmektedir

Ölçüm modeline ilişkin DFA sonuçları incelendiğinde, ki-kare değerinin $\left(c^{2}=1485,02\right.$; $s d=299, p<0.001$ ) anlamlı olduğu görülmektedir. . $\chi^{2} /$ sd değeri kritik değer olarak kabul edilen 3'ten büyük elde edilmiştir. Uyum indeksi değerlerinde ise RMSEA kabul edilebilir değerin üstünde ve GFI kabul edilebilir değerin altında çıkmışıı. Bu sonuçlara göre modelin uyum verdiğini söylemek zordur. Ancak CR ve AVE değerleri ölçüm modelinin uyum geçerliliği gösterdiğini kanıtlamaktadır.

Tablo 3'deki regresyon değerleri incelendiğinde ifade 5'in toplan varyansın sadece 0,04'ünü açıkladığı görülmektedir. Açımlayıcı faktör analizinde karşılaşılan sorun DFA'da kendini göstermektedir. Ifade 5 çıkarılarak yapılan ikinci DFA ise uyum indekslerinde belirgin iyileştirme göstermemiş hatta çok yakın sonuçlar elde edilmiştir.

\subsection{Güvenirlik Analizi}

Güvenirliğini değerlendirmek için Cronbach alfa iç tutarlık katsayısı hesaplanmıştır. Hesaplanan alfa değeri Richmond, McCroskey ve Johnson'un (2003) farklı verilerden elde ettiği değerler ile karşılaştırmalı olarak Tablo 3'de verilmiştir

Tablo 4. Türkçe ve Orijinal Form Cronbach Alpha Katsayıları

\begin{tabular}{|c|c|c|c|}
\hline \multirow{2}{*}{ Türkçe Form } & \multicolumn{3}{|c|}{ Orijinal Form } \\
\cline { 2 - 4 } & Öğretmem verisi & Danıșman verisi & Sevgili verisi \\
\hline 0,94 & 0,92 & 0,93 & 0,93 \\
\hline
\end{tabular}

Görüldüğü üzere elde edilen Cronbach Alpha değeri orijinal forma elde edilen değerlerin üstünde bir değerdir. Bu çalışma için elde edilen Cronbach Alpha değeri kabul edilebilir değer olan 0,80'in (Pallant, 2007) üzerinde bir değerdir.

\section{Sonuç ve Öneriler}

Bu çalışmanın amacı Sözsüz Yakınlık Ölçeği'ni Türkçeye uyarlamak ve geçerlikgüvenirlik analizlerini yapmaktır. Geçerlik testleri için ilk aşamada uygulanan açımlayıcı faktör analizi sonuçlarına göre, tek boyutlu Sözsüz Yakınlık Ölçeği'nde yer alan 26 ifadede beşinci ifadede sorun tespit edilmiştir. Tek boyutlu ölçeklerde, faktör analizi sonucunda ilk faktörde ortaya çıkan rotasyon edilmemiş faktör yüklerinin 0,40'ın üzerinde olması gerekmektedir. Beşinci ifade bu koşulu sağlayamamıştır. Geçerliği test için ikinci aşamada birinci düzey doğrulayıcı faktör analizi uygulanmış ve elde edilen sonuçlar Türkçe formun orijinal form ile yeterli düzeyde uyum sağlamadığını göstermiştir. AFA'da beşinci madde ile ilgili sorun DFA'da da gözlemlenmiştir. Beşinci madde toplam varyansın sadece 0,04'ünü açıklayabilmiştir. Beşinci ifadede, dokunma ile gerçekleşen uzaklaşma eylemi üzerine bir gönderme yaptığı görülmektedir. Buradaki 
uzaklaşma durumu yanıtlayıcılar tarafından sohbeti kesip gitme gibi algılanmış olabilir. Bu ifade "İnsanlarla konuşurken ona dokunulduğunda, kendisine dokunanlarla arasına mesafe koyarak iletişimi sürdürür" şeklinde değiştirilerek yeni bir analiz yapılabilir.

İç tutarlılığı testi için hesaplanan Cronbach alpha değerlerinin orijinal versiyonun üzerinde değerler elde etmesi, iç tutarlılığın ve güvenirliğin sağlandığını göstermektedir.

Aydın ve diğerleri (2013), aynı ölçeği, içinde Türkiye'nin de bulunduğu kültürlerarası bir çalışmada kullanmış ve ölçeğe ilişkin geçerlik ve güvenirlik analizlerini gerçekleştirmiştir. Çalışmada Türkiye için güvenirlik değeri bu çalışmayla paralel bir şekilde yüksek $(0,91)$ çıkarken, geçerlik analizi tek faktör yerine 7 faktör ortaya çıkarmıştır.

Sonuç olarak, Türkçeye uyarlanan Sözsüz Yakınlık Ölçeği geçerlik sorunları yaşasa da, güvenilir bir ölçek olarak görülebilir. Geçerlik sorunu aşmak için farklı örneklemlerde farklı kaynakların sorgulandığı çalışmalar yapılmalı ve geçerlilik testleri uygulanmalıdır. $\mathrm{Bu}$ çalışmada öğrencilere, öğretim üyelerini değerlendirmeleri kolayda örnekleme yöntemi ile istenmiştir. Başka çalışmalarda, örneğin, danışmanların, ebeveynlerin değerlendirilmesi istenerek, geçerlik çalışmaları yapılmalıdır.

\section{Kaynakça}

Andersen, J. (1979). Teacher immediacy as a predictor of teaching effectiveness. In D. Nimmo (Ed.), Communication Yearbook, 3 (pp. 543-559). New Brunswick, NJ: Transaction Books.

Aydin, M. D. et al., (2013). Nonverbal Immediacy and Perception of Learning: A Cross-cultural Survey in Turkey, USA, and China. Hacettepe University Journal of Education, 44, 27-42.

Genç-Kumtepe, E, \& Küçük, M. (2015). Iletişim işlevleri sormacasının türkçe versiyonu için geçerlik ve güvenirlik çalışması. Selçuk Iletişim, 8 (4), 5-31.

Gorham, J. (1988). The relationship between verbal teacher immediacy behaviors and student learning. Communication Education, 37, 40-53.

Hatcher, L. (1994). A step by step approach to using the SAS system for factor analysis and structural squation modelling. NC: SAS Institute

Hooper, D., Coughlan, J., \& Mullen, M. (2008): Structural equation modelling: Guidelines for determining model fit. Electronic Journal of Business Research Methods, 6(1), 53-60.

Fornell, C., \& Larcker, D.F. (1981). Evaluating structural equation models with unobservable variables and measurement error. Journal of Marketing Research 18 (1), 39-50.

Mehrabian, A. (1969). Some referents and measures of nonverbal behavior. Behavior Research Methods and Instrumentation, 1(6), 205-207.

Pallant, J. (2007). SPSS Survival Manual, 3th Ed. NY: McGraw Hill.

Richmond, V. P. (2002). Teaching nonverbal immediacy, in J. L. Chesebro (ed.), Communication for teachers. Boston, MA: Allyn and Bacon, 65-82.

Richmond; V.P., McCroskey, J.C., \& Johnson, A.D. (2003). Development of the nonverbal immediacy scale (NIS): Measures of self and other perceived nonverbal immediach.

Communication Quarterly, 51 (4), 504-517. 
Richmond, V.P., \& McCroskey, J.C. (2000). Nonverbal behavior in human relations, (4th ed.). Needham Heights, MA: Allyn \& Bacon

Tabachnick, B. G. \& Fidell, L.S. (2007). Using multivariate statistics. (5th ed.). Boston: Allyn and Bacon. 